\title{
PENERAPAN METODE TOGAF DAN ZACHMAN UNTUK REKAYASA PERANGKAT ARSITEKTUR PENGADAAN ELEKTRONIK
}

\author{
Ilham M.Said \\ Fakultas Teknik Informatika Universitas Muhammadiyah Gresik \\ ilham@umg.ac.id
}

\begin{abstract}
ABSTRAK
Pilihan teknologi tradisional dalam otomasi proses pengadaan tidak langsung selama ini jatuh pada skenario beli atau membuat sendiri. Perkembangan teknologi e-business kini melebarkan pilihan pada outsourcing (sebelumnya hanya membeli), yang turut menggeser peran aktifitas pengadaan kearah strategis. Berbagai pilihan tersebut dan juga kompleksitas yang terkait dengan pengadaan membutuhkan suatu kerangka arsitektur agar organisasi terhindar dari ketidakselarasan antara infrastruktur IT dengan kebutuhan bisnis pengadaan.

Makalah ini mencoba mengangkat pemodelan arsitektur informasi sebagai sarana integrasi aplikasi eProcurement pada proses bisnis pengadaan barang dan jasa. Kerangka arsitektur informasi TOGAF dan Zachman akan digunakan sebagai acuan sebagai pertimbangan calon pembeli ketika mentransformasikan proses pengadaannya. Fokus arsitektur ditekankan pada fungsionalitas dan kemampuan sistem, faktor-faktor penentunya dalam pengadaan dan pemetaan antara kedua kerangka arsitektur informasi tersebut. Sebagai hasilnya, suatu kerangka terintegrasi yang dapat membantu penerapan aplikasi e-Procurement akan dibahas.
\end{abstract}

Kata kunci : E-Procurement, proses bisnis, Zachman and TOGAF Enterprise Architecture, catalog

\section{Pendahuluan}

Sebelumnya, bagian pengadaan hanyalah dianggap sebagai suatu fungsi yang berdiri sendiri dan aktifitasnya terbatas hanya pada penerimaan permintaan pembelian dari pengguna internal dan meneruskannya menjadi sebuah pembelian barang yang diminta dengan pihak pemasok, baik yang terdaftar maupun yang ad-hoc. Tidak jarang aktifitas pengadaan melibatkan pekerjaan klerikal yang berfokus pada pemrosesan transaksi.

Datangnya teknologi berbasis web, pemrograman yang berorientasi obyek, pengembangan protokol berbasis XML, dan disandingkan dengan model bisnis area pemasaran yang inovatif, memulai era baru yang membawa dampak mendalam pada proses bisnis pengadaan dan sistemnya, terutama pada pengadaan barangbarang tidak langsung (selanjutnya disebut pengadaan tidak langsung - indirect procurement) [2] Bahkan, transformasi ini tidak terbatas pada pembelian saja, tapi juga mempengaruhi dan dipengaruhi oleh model e-business dan proses lainnya. Yang awalnya merupakan suatu sistem pengadaan terfokus yang sempit, telah bertransformasi menjadi jejaring teknologi, pasar, dan strategi bisnis yang berdampak melampaui fungsi pembelian.

Davila, Gupta, dan Palmer [2] menyatakan bahwa perusahaan menggunakan strategi yang berbeda dalam mengadopsi/mengintegrasikan teknologi e-procurement berdasarkan manfaat dan risiko yang berhubungan dengan posisi bersaing dan lingkungan. Strategi tersebut berkisar pada adopsi yang agresif dan adopsi konservatif. Fokus makalah ini adalah mengupas sisi adopsi konserfatif. Adanya risiko dan manfaat tersebut mengharuskannya adanya upaya integrasi dan pemahaman yang baik dalam mengimplementasikan infrastruktur teknologi dan aplikasi pengadaan elektronik (selanjutnya disebut e-procurement) ke dalam aspek-aspek dalam proses bisnis pengadaan. Pilihan teknologi tradisional dalam otomasi proses bisnsi selama ini jatuh pada keputusan make or buy decision. Kini outsourcing menambah pilihan dalam proses integrasi ini.

Berbagai pilihan tersebut dan juga kompleksitas yang terkait dengan pengadaan membutuhkan suatu kerangka arsitektur agar organisasi terhindar dari ketidakselarasan antara infrastruktur IT dengan kebutuhan bisnis pengadaan. Makalah ini membahas secara teoritis pendekatan arstektural informasi yang terbaik dalam integrasi aplikasi e-Procurement pada proses bisnis pengadaan barang dan jasa tidak langsung dengan menggunakan kerangka arsitektur informasi TOGAF dan Zachman Faktor seperti struktur pasar, fungsionalitas dan kemampuan sistem, faktor-faktor penentunya keberhasilan, proses bisnis pengadaan dan kedayagunaan pemetaan antara kedua kerangka arsitektur informasi tersebut merupakan indikator dalam merancang arsitektur informasi untuk integrasi eprocurement. Sebagai hasilnya, suatu kerangka terintegrasi yang dapat membantu penerapan aplikasi e-Procurement akan dibahas. 


\section{Pengadaan}

Pengadaan (Procurement) adalah proses antar- organisasi yang dilakukan oleh dua peran: pembeli dan penjual dengan tujuan si pembeli membeli barang atau jasa dari penjual. Hal ini dikerjakan dengan adanya pertukaran berbagai dokument, diikuti dengan pertukaran barang dan uang. Terdapat perbedaan yang cukup jelas antara pengadaan dengan pembelian, dimana pembelian hanyalah semata-mata aktifitas pembayaran barang dan jasa. Sementara pengadaan, selain proses pembelian, berbicara lebih jauh yang dapat dipandang sebagai sebuah siklus. Siklus tersebut dapat dipandang sebagai serangkaian peristiwa permintaan barang, persetujuan, hingga ke proses pembayarannya. Aktifitas pengadaan dapat dibedakan menjadi dua poin utama [1] : (1) Pengadaan Tidak Langsung dan (2) Pengadaan Langsung.

Indirect procurement mencerminkan proses pengadaan untuk komoditi yang tidak menghasilkan barang jadi. Pengadaan ini meliputi dua jenis barang yakni barang-barang keperluan kantor (sering disebut Operating Resource Management - ORM) dan barang-barang keperluan pemeliharaan (sering disebut Maintenance, Repair, and Operation - MRO). Kedua jenis barang ini memiliki nilai beli dari yang harga per unitnya rendah seperti perlengkapan hingga yang harga per unitnya cukup tinggi seperti jasa konsultasi dan peralatan berat. Jenis pengadaan langsung meliputi komoditi yang berkaitan secara langsung untuk menghasilkan produk jadi. Biasanya nilai dari bahan baku ini sangat besar dan memiliki proporsi yang cukup siginifikan dalam penghintungan harga pokok produk per unitnya. Contoh pengadaan langsung antara lain pengadaan gas alam untuk pabrikasi pupuk, pengadaan besi untuk pengolahan baja, dan lainnya. Pengadaan MRO terdiri dari urutan peristiwa- peristiwa berikut.

\section{Pencarian Katalog}

2. Membandingkan Barang

3. Membuat permintaan

4. Menyetujui permintaan

5. Memesan Barang

6. Memenuhi Order

7. Membayar pemasok

Untuk memahami proses bisnis di atas sangat kritikal agar menjamin bahwa usaha penyelarasaan bisnis dengan sistem informasi tercipta secara menyeluruh dalam organisasi. Oleh karenanya, direkomendasikan untuk merancang kerangka arsitektur informasi yang memungkinkan perusahaan untuk mengelola dan memperoleh gambaran menyeluruh dari indirect procurement dan menilai bagaimana hal ini mempengaruhi proses bisnis lainnya. Contoh gambaran rinci dari proses indirect procurement adalah pembelian barang tertentu dari satu pemasok atau membandingkan penawaran berbagai pemasok, mengelola katalog berbagai pemasok, dan menangani penerimaan barang [5].

\section{3. e-Procuremement dan Faktor-faktor penentu}

Migrasi aplikasi ke platform e-business pada aktifitas procurement diyakini oleh beberapa peneliti memberikan dampak positif, antara lain pengurangan biaya, menyederhanakan proses bisnis pengadaan, menyederhanakan ukuran pusat pertanggungjawaban pembelian, meningkatkan pelayanan pelanggan, mengurangi fungsi pekerjaan, meningkatkan partisipasi peserta bagian pengadaan, mengurangi error, dan menyajikan informasi yang lebih tepat $[1,2,4,8]$. e-Procurement memiliki beberapa jenis seperti Tabel 1 dibawah ini.

Tabel 1 Jenis e-Procurement 


\begin{tabular}{|c|c|}
\hline Model Da & Karakteristik \\
\hline EDI Networks & $\begin{array}{l}\text { - } \begin{array}{l}\text { Kumpulan kecil rekanan } \\
\text { dagang }\end{array} \\
\text { - Fungsionalitas transaksi yang } \\
\text { sederhana } \\
\text { - Batch processing } \\
\text { - Value Added Network(VAN) }\end{array}$ \\
\hline $\begin{array}{l}\text { Corporate } \\
\text { Procurement } \\
\text { Portals }\end{array}$ & $\begin{array}{l}\text { - } \begin{array}{l}\text { Meningkatkan pengendalian } \\
\text { atas proses pengadaan }\end{array} \\
\text { - Katalog yang spesifik, dan } \\
\text { banyak } \\
\text { - } \begin{array}{l}\text { Dukungan terhadap analisis } \\
\text { pengeluaran dan kinerja } \\
\text { pemasok } \\
\text { - Fokus bahan baku tidak } \\
\text { langsung }\end{array}\end{array}$ \\
\hline $\begin{array}{l}\text { Trading } \\
\text { Exchanges: } \\
\text { First Generation } \\
\text { (community } \\
\text { oriented) }\end{array}$ & $\begin{array}{l}\text { - Muatan industri, klasifikasi } \\
\text { kerja, berita } \\
\text { Muatan produk dan layanan } \\
\text { pengumpulan katalog }\end{array}$ \\
\hline $\begin{array}{l}\text { Trading } \\
\text { Exchanges: } \\
\text { Third } \\
\text { Generation }\end{array}$ & $\begin{array}{l}\text { - Penyelarasaan operasi antar } \\
\text { rekanan (real time) } \\
\text { - Transparansi proses yang } \\
\text { memfasilitasi restrukturisasi }\end{array}$ \\
\hline
\end{tabular}

\section{Sumber: Mark Dale, 2006[1]}

Perusahaan perlu menelaah secara mendalam agar manfaat bisnis yang diargumentasikan para peneliti sebelumnya dapat tercapai. Oleh karenanya, dalam konteks pengadaan MRO, perusahaan penting untuk mengetahui faktor penentu keberhasilan proses integrasi ini. Vondrák [8] mengajukan tiga faktor yang penting untuk diperiksa sebagai dimensi penentu dalam menilai derajat solusi e-Procurement pada proses bisnis yang ada.

\subsection{Aliran Kerja Otomatis}

Derajat solusi dinilai dari kemampuan aplikasi untuk menjalankan proses tanpa campur tangan dokumen berbasis manual. Teknologi yang memungkinkan aliran kerja otomatis ini disebut workflow engine. Tujuan dari workflow engine adalah untuk mengotomasi proses penyerahan antar satu proses dengan proses lain. Tanpa aplikasi aliran kerja, tidak ada cara otomatis untuk mengkoordinasi dan mendorong aturan bisnis, yang berlaku untuk seluruh proses. Idealnya sebuah worfklow engine harus memiliki kemampuan berikut:

1. Menangani setidaknya langkah sampai ke penerbitan order MRO.

2. Menangani skenario rute menurut tipe barang MRO yang dibeli.

3. Menangani skenario rute yang berbeda menurut item permintaan user.

4. Memungkinkan workflow berbeda dikonfigurasikan oleh pengguna administrasi, bukan programmer. Dari kaca mata integrasi ke proses pengadaan MRO, otomasi aliran kerja dapat dicapai melalui tiga alternatif:

1. Membeli aplikasi e-procurement dengan workflow otomotis

2. Meng-outsource penyedia katalog yang memiliki fungsi workflow

3. Mengintegrasikan dengan workflow engine yang ada

\subsection{Manajemen Katalog}

Integrasi e-Procurement lebih jauh juga mendayagunakan pihak internal untuk melakukan aktifitas pencarian barang, pembandingan berbagai aspek kualitas barang para pemasok melalui katalog online, dan permintaan pembelian. Katalog online ekuivalen dengan katalog manual. Minimalnya, katalog tersebut mengandung deskripsi produk, harga dan waktu antar.

Kebanyakan vendor e- Procurement membutuhkan adanya database lokal yang mengandung konten dari katalog online tersebut. Aktifitas tersebut membutuhkan adanya replikasi dan rasionalisasi data. Namun kebanyakan projek intergrasi e-Procurement menghadapi masalah untuk database yang direplikasi dan dirasionalisasi tadi. Rekomendasi untuk kesulitan ini adalah dengan meng-outsource katalog oleh lembaga intermediasi yang memiliki transaksi dengan berbagai supplier relevan yang juga mengagregasikan berbagai katalog menjadi satu.

\subsection{Integrasi Supplier}

Integrasi supplier mencerminkan perubahan unik karena teknologi yang terkait dengan internet. Isu integrasi pemasok berkisar pada dua titik sentuh pemasok. Dua titik tersebut adalah proses penerbitan/penyerahan order dan katalog online. Penerbitan order adalah titik dimana batas sistem pengadaan internal telah tercapai dan 
membutuhkan adanya aktifitas pengadaan eksternal, yakni dilakukan pemasok. Tepatnya, proses pengorderan pada sisi pembeli harus dilanjutkan dengan proses pemenuhan pesanan (fulfilment) oleh sisi pemasok/penjual. Dua teknologi utama dapat dipertimbangkan, Electronic Data Interchange (EDI) dan eXtensible Markup Language $(X M L)$.

Baik EDI maupun XML memiliki dimensi tersendiri, walaupun XML disinyalir mendapat tempat yang lebih luas dalam aktifitas e-Business yang akan datang. Katalog online membutuhkan format standar yang dapat mengakomodasi semua tipe data untuk selanjutnya diagregasikan ke database baik oleh pihak intermediasi atau database lokal klien penyelenggara e- Procurement. The open Buying on the internet (OBI) adalah standar yang mengharuskan para pemasok untuk mengelola katalog mereka dan membagi akses informasi tersebut baik untuk kepentingan in-house atau outsourced catalogue.

Ketiga aspek dalam e-Procurement tersebut mengharuskan perusahaan untuk memetakan segala perencanaan dan kebutuhan bisnis ke dalam suatu arsitektur yang memungkinkan

reusability komponen dikemudian hari untuk kepentingan pengembangan lanjut. Untuk itulah diperlukan arsitektur informasi dalam enterprise.

\section{Arsitektur informasi}

Seperti yang diungkapkan pada bab pendahuluan, migrasi ke basis elektronik membutuhkan perencanaan yang mengharuskan adanya pemetaan risiko dan kebutuhan tepat untuk merealisasikan strategic alignment antara bisnis dengan IT. Dalam suatu survey oleh Institute for Enterprise Architecture Development pada 2005, diperoleh hasil bahwa mayoritas perusahaan yang menerapkan arsitektur enterprise (khususnya arsitektur informasi) berhasil menyelaraskan struktur IT dengan tujuan bisnis. Diantara sasaran yang ada adalah penggunaan kembali (reuse) infrastruktur IT yang ada dan penyebaran metode normal untuk manajemen proyek dan pengembangan sistem di seluruh perusahaan.

Arsitektur Informasi (AI) merupakan model konstruksi komprehensif atas data, proses bisnis, dan asset-aset teknologi informasi dalam perusahaan. AI menghadirkan pandangan berjangka panjang atas berbagai proses, sistem, dan teknologi yang berdasarkan suatu rancangan yang konsisten dan koheren sehingga proyek-proyek individu dapat menghasilkan sebuah kapabilitas daripada memenuhi kebutuhan secara instant. Suatu kerangka AI menghubungkan misi-misi organisasi, sasaran, dan tujuan proses bekerja serta infrastruktur yang dibutuhkan untuk melaksanakannya. Penulis menggunakan dua kerangka arsitektur informasi yang banyak dikenal dalam menerapkan tata kelola eProcurement.

\subsection{TOGAF}

TOGAF merupakan metode terinci dan serangkaian alat pendukung untuk mengembangkan suatu arsitektur informasi. Kerangka ini mempertimbankan aset perusahaan dan berfokus pada berbagai aplikasi bisnis missioncritical dan memungkinkan perancangan arsitektur informasi yang customized. TOGAF merupakan serangkaian metode dan alat untuk membangun variasi arsitektur, termasuk arsitektur bisnis, data, aplikasi dan teknologi. The Architecture Development Method (ADM) adalah fitur penting yang memungkinkan perusahaan mendefinisikan kebutuhan bisnis dan membangun arsitektur spesifik untuk memenuhi kebutuhan itu. ADM terdiri dari fase fase yang dibutuhkan dalam membangun arsitektur sistem informasi perusaaan. Tabel 2 menjelaskan fase yang perlu dilalui dalam kerangka ADM TOGAF.

\begin{tabular}{|c|c|c|}
\hline Phase & Overview & Key Steps \\
\hline $\begin{array}{c}\text { Preliminary } \\
\text { Phase }\end{array}$ & $\begin{array}{l}\text { Framework and } \\
\text { Principles }\end{array}$ & $\begin{array}{c}\text { Get everyone on } \\
\text { board with the plan }\end{array}$ \\
\hline Phase A & $\begin{array}{c}\text { Architecture } \\
\text { Vision }\end{array}$ & $\begin{array}{l}\text { Define scope and } \\
\text { vision and map } \\
\text { overall strategy }\end{array}$ \\
\hline
\end{tabular}




\begin{tabular}{|c|c|c|}
\hline Phase B & $\begin{array}{c}\text { Business } \\
\text { Architecture }\end{array}$ & $\begin{array}{l}\text { Describe current } \\
\text { and target business } \\
\text { architectures and } \\
\text { determine the gap } \\
\text { between them }\end{array}$ \\
\hline Phase $C$ & $\begin{array}{c}\text { Information } \\
\text { System } \\
\text { Architecture }\end{array}$ & $\begin{array}{c}\text { Develop target } \\
\text { architectures for } \\
\text { data and } \\
\text { applications }\end{array}$ \\
\hline Phase D & $\begin{array}{l}\text { Technology } \\
\text { Architecture }\end{array}$ & $\begin{array}{l}\text { Create the overall } \\
\text { target architecture } \\
\text { to be implemented } \\
\text { in future phases }\end{array}$ \\
\hline Phase E & $\begin{array}{c}\text { Opportunities and } \\
\text { Solutions }\end{array}$ & $\begin{array}{c}\text { Develop overall } \\
\text { strategy, determine } \\
\text { what to buy, build } \\
\text { or reuse, and how to } \\
\text { implement } \\
\text { architecture from } \\
\text { Phase D }\end{array}$ \\
\hline Phase F & $\begin{array}{l}\text { Migration } \\
\text { Planning }\end{array}$ & $\begin{array}{l}\text { Prioritize projects } \\
\text { and develop a } \\
\text { migration plan }\end{array}$ \\
\hline Phase G & $\begin{array}{c}\text { Implementation } \\
\text { Governance }\end{array}$ & $\begin{array}{l}\text { Determine how to } \\
\text { provide oversight to } \\
\text { the implementation }\end{array}$ \\
\hline Phase H & $\begin{array}{l}\text { Architecture } \\
\text { Change } \\
\text { Management }\end{array}$ & $\begin{array}{c}\text { Monitor the running } \\
\text { system for } \\
\text { necessary changes, } \\
\text { and determine } \\
\text { whether or not to } \\
\text { restart the cycle }\end{array}$ \\
\hline
\end{tabular}

\subsection{Zachman Framework (ZF)}

ZF berfokus pada usaha menjamin agar seluruh aspek dalam organisasi terorganisasi dengan baik dan menunjukkan hubungan yang jelas. Kerangka ini menyediakan cetak biru bagi arsitektur informasi dengan menyejikan taksonomi untuk berbagai pandangan, model, dan bangunan yang diinginkan perusahaan dalam membangun sistem informasi mereka. Pada intinya, kerangka ZF menunjukan prinsip-prinsip sebagai berikut:

1. Sebuah sistem lengkap dapat dimodelkan dengan menjawab pertanyaan what, how, where, who, when and why pada bangunan sistem informasi.

2. Enam pandangan menangkap seluruh model kritikal untuk pembangunan sistem.

3. Kolom menunjukan abstraksi yang berbeda dan tanpa urutan.

4. Setiap sel mencerminkan perspektif unik.

Penulis menggunakan hasil kerja Hay [3] untuk menampilan berbagai perspektif dalam ZF. Gambar 1 menggambarkan berbagai pandangan tersebut dalma sel-sel yang saling berkaitan terkait pada sistem informasi. 
Gambar 1 Berbagai pandangan pada Zachman Framework Menurut Hay (Disunting)

\begin{tabular}{|c|c|c|c|c|c|c|}
\hline & Data & Function & Network & People & Time & Motivation \\
\hline Scope & $\begin{array}{l}\text { List of items } \\
\text { important to } \\
\text { the } \\
\text { enterprise }\end{array}$ & $\begin{array}{l}\text { List of } \\
\text { process the } \\
\text { enterprise } \\
\text { performs }\end{array}$ & $\begin{array}{l}\text { List of locations } \\
\text { where the } \\
\text { enterprise } \\
\text { operates }\end{array}$ & $\begin{array}{l}\text { List of } \\
\text { organizational } \\
\text { units }\end{array}$ & $\begin{array}{l}\text { List of business } \\
\text { events / cycles }\end{array}$ & $\begin{array}{l}\text { List of } \\
\text { business goals } \\
\text { / strategies }\end{array}$ \\
\hline $\begin{array}{l}\text { Enterpris } \\
\text { e Model }\end{array}$ & $\begin{array}{l}\text { Entity } \\
\text { relationship } \\
\text { diagram }\end{array}$ & $\begin{array}{l}\text { Business } \\
\text { process } \\
\text { model }\end{array}$ & Logistics network & $\begin{array}{l}\text { Organization } \\
\text { chart with roles, } \\
\text { skill sets and } \\
\text { security issues }\end{array}$ & $\begin{array}{l}\text { Business master } \\
\text { schedule }\end{array}$ & $\begin{array}{l}\text { Business } \\
\text { rules }\end{array}$ \\
\hline $\begin{array}{l}\text { System } \\
\text { Model }\end{array}$ & Data Model & $\begin{array}{l}\text { Essential } \\
\text { data flow } \\
\text { diagram }\end{array}$ & $\begin{array}{l}\text { Distributed } \\
\text { system } \\
\text { architecture } \\
\end{array}$ & $\begin{array}{l}\text { Human } \\
\text { interaction } \\
\text { architecture } \\
\end{array}$ & $\begin{array}{l}\text { Dependency } \\
\text { diagram, entity } \\
\text { life history }\end{array}$ & $\begin{array}{l}\text { Business rule } \\
\text { model }\end{array}$ \\
\hline $\begin{array}{l}\text { Technolo } \\
\text { gy model }\end{array}$ & $\begin{array}{l}\text { Data } \\
\text { architecture } \\
\text { map to } \\
\text { legacy data }\end{array}$ & $\begin{array}{l}\text { System } \\
\text { design: } \\
\text { structure } \\
\text { chart, pseudo } \\
\text { code }\end{array}$ & $\begin{array}{l}\text { System } \\
\text { architecture }\end{array}$ & $\begin{array}{l}\text { User Interface; } \\
\text { security design }\end{array}$ & $\begin{array}{l}\text { Control flow } \\
\text { diagram }\end{array}$ & $\begin{array}{l}\text { Business rule } \\
\text { design }\end{array}$ \\
\hline $\begin{array}{l}\text { Detailed } \\
\text { representat } \\
\text { ions }\end{array}$ & $\begin{array}{l}\text { Data design, } \\
\text { physical } \\
\text { storage design }\end{array}$ & $\begin{array}{l}\text { Detailed } \\
\text { program } \\
\text { design }\end{array}$ & $\begin{array}{l}\text { Network } \\
\text { architecture }\end{array}$ & $\begin{array}{l}\text { Screens, security } \\
\text { architecture }\end{array}$ & $\begin{array}{l}\text { Timing } \\
\text { definitions }\end{array}$ & $\begin{array}{l}\text { Rule } \\
\text { specification } \\
\text { in program } \\
\text { logic }\end{array}$ \\
\hline $\begin{array}{l}\text { Functionin } \\
\text { g system }\end{array}$ & $\begin{array}{l}\text { Converted } \\
\text { data }\end{array}$ & $\begin{array}{l}\text { Executable } \\
\text { programs }\end{array}$ & $\begin{array}{l}\text { Communications } \\
\text { facilities }\end{array}$ & $\begin{array}{l}\text { Trained personal } \\
\text { using the system }\end{array}$ & Business events & Enforced rules \\
\hline
\end{tabular}

Gambar 1 Berbagai pandangan pada Zachman Framework Menurut Hay (Disunting)

\section{Pemetaan TOGAF dan Zachman pada e- Procurement}

ZF dipengaruhi oleh sejumlah prinsip arsitektur dan mencanangkan serangkaian deliverables untuk menciptakan arsitektur informasi. Sementara ADM TOGAF merekomendasikan cara mendefinisikan prinsip-prinsip dan menghadirkan beragam deliverable yang mungkin berdasarkan pada kebutuhan dan sasaran spesifik perusahaan. Hal berikut ini memberikan alasan untuk memetakan ADF ke dalam ZF:

a. Pandangan yang direkomendasikan TOGAF tidak mencakup seluruh 36 sel seperti pada ZF (Tanpa perspektif motivasi).

b. ZF mengabaikan tata kelola sebagai pandangan manajemen yang diakomodasi TOGAF.

c. ZF tidak mendefinisikan proses dalam membangun perspektif berdasarkan tujuan dari arsitektur enterprise.

d. TOGAF tidak mencanangkan suatu deliverable yang spesifik atau jelas.

Proses integrasi e-Procurement dapat dilakukan dengan terlebih dahulu membuat arsitektur informasi hasil dari kombinasi ADM TOGAF dan ZF. Bagian yang ditebalkan dan diberi bayang-bayang pada gambar 1 merupakan abstraksi tingkat tinggi yang menunjukan area dimana prinsip pengembangan arsitektur TOGAF dipetakan pada prinsip hubungan perspektif seluruh sel dalam ZF. Selanjutnya integrasi e-Procurement dapat mengacu pada arsitektur sistem informasi hasil pemetaan TOGAF dengan ZF. Gambar 2 menunjukkan satu pandangan arsitektur yang mungkin diikuti dalam mengintegrasikan e- Procurement. Kerangka tersebut menunjukkan area spesifik dimana integrasi pengadaan MRO difokuskan dan dimana ADM digunakan sebagai alat untuk mencapai sistem target. Dapat dilihat bahwa arsitektur informasi untuk integrasi e- Procurement disusun hanya pada 4 level abstrasi yakni scope, enterprise model system model dan technology model

\section{Kesimpulan}

Dari hasil analisis ini, dapat dilihat bahwa secara individu, kedua kerangka arsitektur informasi tersebut tidak dapat sepenuhnya memuaskan kebutuhan dalam mengelola sistem informasi untuk integrasi e-Procurement MRO ke proses pengadaan intinya. Arsitektur informasi secara utama terdiri atas: arsitektur dasar, rencana transisi, dan arsitektur target. Untuk dapat memenuhi kebutuhan tersebut, diperlukan gabungan rancangan arsitektur informasi yang menjawab kebutuhan multi persepektif atas e- Procurement dan langkah-langkah yang perlu ditempuh untuk mengintegrasikan proses pengadaan. 
Artikel ini menunjukkan bahwa faktor keberhasilan integrasi e-Procurement seperti otomasi workflow, katalog online, dan proses integrasi pemasok dapat diidentifikasi dan dikelola dalam membangun mengintegrasikan e-Procurement ke dalam proses bisnis inti. Dengan arsitektur informasi memberikan

\begin{tabular}{|c|c|c|c|c|c|c|}
\hline Scope & $\begin{array}{c}\text { Procurement } \\
\text { Data }\end{array}$ & $\begin{array}{c}\text { Procuremen } \\
\text { t processe }\end{array}$ & $\begin{array}{c}\text { Global } \\
\text { operation }\end{array}$ & $\begin{array}{l}\text { Purchasing, } \\
\text { Finance and } \\
\text { Product } \\
\text { Development }\end{array}$ & $\begin{array}{c}\text { Procureme } \\
\text { nt Cycle }\end{array}$ & $\begin{array}{c}\text { Supplier- } \\
\text { buyer alliance }\end{array}$ \\
\hline $\begin{array}{c}\text { Enterprise } \\
\text { Model }\end{array}$ & $\begin{array}{c}\text { catalogue } \\
\text { management, } \\
\text { dispatch data, } \\
\text { and supplier }\end{array}$ & $\begin{array}{c}\text { Select } \\
\text { vendor, pay } \\
\text { supplier, } \\
\text { search } \\
\text { catalogue }\end{array}$ & $\begin{array}{l}\text { Logistics } \\
\text { network }\end{array}$ & $\begin{array}{l}\text { Responsible } \\
\text { division, cost } \\
\text { and } \\
\text { management } \\
\text { accounting }\end{array}$ & $\begin{array}{c}\text { Gant } \\
\text { Chart for } \\
\text { selected } \\
\text { procureme } \\
\text { nt }\end{array}$ & $\begin{array}{l}\text { Workflow } \\
\text { automation }\end{array}$ \\
\hline .System Model & $\begin{array}{c}\text { ERD for } \\
\text { enterprise } \\
\text { procurement } \\
\text { data }\end{array}$ & $\begin{array}{l}\text { DFD to } \\
\text { primitive } \\
\text { level }\end{array}$ & $\begin{array}{c}\text { Inter } \\
\text { company } \\
\text { System } \\
\text { client- } \\
\text { server arc }\end{array}$ & $\begin{array}{c}\text { Responsible } \\
\text { user and } \\
\text { deliverable }\end{array}$ & $\begin{array}{l}\text { Dependenc } \\
\text { y diagram, } \\
\text { entity life } \\
\text { history }\end{array}$ & $\begin{array}{l}\text { Procurement } \\
\text { procedure }\end{array}$ \\
\hline $\begin{array}{c}\text { Technology } \\
\text { Model }\end{array}$ & $\begin{array}{c}\text { OBI-based } \\
\text { catalogue data } \\
\text { design and } \\
\text { aggregated } \\
\text { multiple } \\
\text { supplier's data, } \\
\text { XML-based } \\
\text { order/fulfilment } \\
\text { format }\end{array}$ & $\begin{array}{c}\text { XML/EDI - } \\
\text { based } \\
\text { documents } \\
\text { consensus, } \\
\text { Order- } \\
\text { Fulfilment } \\
\text { automation }\end{array}$ & $\begin{array}{c}\text { Intercompa } \\
\text { ny } \\
\text { Procureme } \\
\text { nt } \\
\text { connection }\end{array}$ & $\begin{array}{c}\text { Database } \\
\text { administrator, } \\
\text { Web } \\
\text { programmer, } \\
\text { and Business } \\
\text { Analyst }\end{array}$ & $\begin{array}{l}\text { Throughp } \\
\text { ut time for } \\
\text { processing } \\
\text { one } \\
\text { requisition }\end{array}$ & $\begin{array}{c}\text { Embedded } \\
\text { workflow } \\
\text { automation } \\
\text { and enabling } \\
\text { hand-offs }\end{array}$ \\
\hline
\end{tabular}

\section{Gambar 2. e-Procurement Mapping ADM to Zachman Framework}

Kemudahan bagi perusahaan untuk melakukan perencanaan dan implementasi sistem pengadaan dari sistem informasi yang kini ada hingga tercapai sistem yang terintegrasi secara baik, sehingga membuktikan manfaat yang diperoleh atas aplikasi pengadaan MRO sebagaimana yang telah diteliti oleh para penulis sebelumnya. Penulis merekomendasikan untuk menggunakan kedua kerangka untuk mencapai tujuan akhir yakni suatu solusi eProcurement yang adaptif dan terintegrasi secara penuh.

\section{Daftar Pustaka}

[1] Dale, Mark., 2006, E-Procurement, Material in E- Procurement Lecturer, Melbourne, Australia.

[2] Davila, Antonio; Mahendra Gupta; and Richard J. Palmer, 2002, Moving Procurement Systems to the Internet: The Adoption and Use of E-Procurement Technology Models, Working Paper, Oling Business School, Washington University in St. Louis, viewed on 10 September 2007 from http://www.olin.wustl.edu/workingpapers/pdf/200 2-04-001.pdf

[3] Hay, DC 2000, 'A Different Kind of Life Cycle: The Zachman Framework', viewed on 28 September 2006, from $<$ http://webraft.its.unimelb.edu.au/615671/prot/We ek\%208/A\%20Different\%20Kind\%20of\%20Life \%20Cycle\%20-\%20The\%20Zachman.pdf>

[4] Osmonbekov,Talai; Daniel C. Bello; and David I Gilliland, 2002, Adoption of electronic commerce tools in business procurement: enhanced buying center structure and processes, Journal of business and industrial marketing, vol.17 no.2/3, pp.151- 166 .

[5] Segev, A and Gebauer, J., 2001, B2B Procurement and Marketplace Transformation, Information Technology and Management, Vol. 2, pp 241-260, 
[6] Sowa, JF and Zachman, JA, 1992, Extending and formalizing the framework for information systems architecture, IBM Systems Journal, vol. 31, no. 3.

[7] The Open Group, 2003, The Open Group Architecture Framework) Version 8.1 "Enterprise Edition", viewed on 10 October 2006, from <http://webraft.its.unimelb.edu.au/615671/prot/We ek\%209/TOGAF\%20Version\%208.1.pdf>.

[8] Vondrák, Leoš, 2000, eProcurement Architecture, viewed on 20 October 2007 from <http://si.vse.cz/archiv/clanky/2000/vondrak.pdf\#s earch=\%22e-procurement\%20architecture\%22> 